\title{
AVALIAÇÃO DE UNIDADES DE HABITAÇÃO DO PROGRAMA MCMV, NO SUL CATARINENSE
}

PIAZZA, Cristina Maria da Silveira

Caixa Econômica Federal, e-mail: arq.cristina_piazza@yahoo.com.br

\begin{abstract}
RESUMO
Este trabalho foi apresentado como pré-requisito para aprovação em curso de especialização e nele se propôs avaliar composições dos espaços de unidades habitacionais em projetos arquitetônicos de empreendimentos do Programa Minha Casa, Minha Vida, construídas na região de Criciúma/SC, através de uma avaliação comparativa tanto qualitativa quanto quantitativa nos quesitos relativos à forma, geometria e funcionalidade, em amostra composta por quatro empreendimentos nos municípios de Balneário Rincão, Criciúma, Içara e Forquilhinha. A avaliação se deu através de metodologias apropriadas a cada caso, sendo a geometria analisada sob a ótica de Ching (1999) e Clark \& Pause (1997), a relação da forma através de Horton (1932) e Haggett (1965), a forma através da avaliação da análise de performance do projeto de March (1970) e do índice de compacidade de Mascaró (2006). Por outro lado, a funcionalidade buscará relacionar os componentes estáticos e dinâmicos definidos por Clark \& Pause (1997). O estudo realizado comprova que pequenos ajustes na geometria e forma das áreas das unidades habitacionais podem trazer sensíveis mudanças na funcionalidade, garantindo habitabilidade e conforto ambiental para os beneficiários do PMCMV.
\end{abstract}

Palavras-chave: Habitação de Interesse Social, Avaliação Comparativa, Geometria, Forma, Funcionalidade.

\begin{abstract}
This work was presented as a prerequisite for approval in the course of specialization, and it was proposed to evaluate the composition of housing units in architectural projects of the Minha Casa, Minha Vida' Program, built in the region covered by Criciúma/SC, through an evaluation comparing both qualitative and quantitative aspects of form, geometry and functionality, in a sample composed of four projects in the municipalities of Balneário Rincão, Criciúma, Içara and Forquilhinha. The evaluation was based on methodologies appropriate to each case, geometry being analyzed from the perspective of Ching (1999) and Clark \& Pause (1997), the form's relationship by Horton (1932) and Haggett (1965), the form will be given through the evaluation of the performance analysis of the project of March (1970) and the index of compactness of Mascaró (2006). On the other hand the functionality will seek to relate the static and dynamic components defined by Clark \& Pause (1997). The study shows that small adjustments in the geometry and shape of the areas of social housing can bring about sensible changes in functionality, guaranteeing habitability and environmental comfort for the PMCMV beneficiaries.
\end{abstract}

Keywords: Housing of Social Interest, Comparative Evaluation, Geometry, Form, Functionality.

\section{INTRODUÇÃO}

Segundo dados da Fundação João Pinheiro (2014:31), o estado de Santa Catarina possui um déficit habitacional total de 204.648 unidades. Enquanto no município de Criciúma o déficit no ano de $2013^{i}$ era de 5.200 moradias, segundo a Secretaria Municipal do Sistema Social de Criciúmaii.

PIAZZA, C. M. S. Avaliação de unidades de habitação do Programa MCMV, no Sul Catarinense. In: SIMPÓSIO BRASILEIRO DE QUALIDADE DO PROJETO NO AMBIENTE CONSTRUÍDO, 6., 2019, Uberlândia. Anais... Uberlândia: PPGAU/FAUeD/UFU, 2019. p. 1088-1100. DOI https://doi.org/10.14393/sbqp19099. 
O problema habitacional no país remonta ao final do século XIX, decorrente do fim da escravidão e a migração destes do campo para as cidades quando "O fim da escravidão fez com que milhares de negros fossem expulsos do campo e migrassem para a cidade" (MOTTA, 2017), concomitante à chegada de muitos imigrantes, que vieram a trabalho ao Brasil, e decidem se fixar no país em busca de melhores oportunidades de vida. Este evento não foi diferente na região de Criciúma/SC, que se desenvolveu por conta de suas atividades mineradoras.

Desde aquela época o Estado brasileiro não dispunha de controle ou estratégia de atuação no campo habitacional, o que tornou a situação ainda mais sensível. O aumento populacional desordenado nos grandes centros sem um planejamento adequado, e a eminente necessidade de moradia, fez com que o mercado imobiliário se voltasse ao atendimento desta necessidade. Desta forma, Pagani (2013, p.3) complementa apontando que neste momento se deu o início do processo de formação dos bairros populares na cidade de Criciúma e região, compatíveis com o salário das famílias, contudo, sem infraestrutura adequada, o que constituía risco, inclusive, à saúde pública, forçando o Estado a intervir, porém de forma ainda incipiente.

A partir de 2003, a política habitacional do país, começa um novo momento através da atuação de programas federais como o Minha Casa Minha Vida (PMCMV) que criou condições de acesso à moradia a todos os cidadãos, aliado à atuação do Estado, através do fornecimento de subsídios, para que as famílias de menor poder aquisitivo tenham acesso à moradia. Porém, nem sempre as unidades habitacionais propostas e construídas correspondem aos anseios e necessidades dos beneficiários.

Considerando que para a Constituição Federal (1988) "a habitação é um direito social do cidadão" e onde o Estatuto da Cidade (2001) estabelece "a função social da propriedade" este estudo propõe avaliar os espaços internos de unidades de habitação de empreendimentos habitacionais, de maneira que a análise comparativa entre as plantas possa demonstrar, qualitativamente e quantitativamente, a que melhor reúne estes atributos.

\section{POLÍTICAS HABITACIONAIS DE INTERESSE SOCIAL NO BRASIL E NA REGIÃO SUL CATARINENSE}

Durante muito tempo o Estado brasileiro não atuava na promoção de habitação à população de menor renda, pois dirigia seus esforços ao crescimento econômico do país. Grande parte da população desta faixa econômica morava de aluguel, o que correspondia à produção rentista daquele período, e que, muitas vezes, comprometia todo o salário da família. Buscavam, então, nos bairros populares condições compatíveis com seus rendimentos. Porém tais bairros localizavam-se afastados do centro e das áreas de trabalho, não dispondo de infraestrutura, transporte público e as moradias configuravam situações precárias de insalubridade (BONDUKI, 2004).

A habitação popular passou a ser um problema quando o poder público identificou que essas constituíam risco à saúde pública, dado à precariedade destas e dos muitos surtos epidêmicos (PAGANI, 2013, p.3).

Logo as iniciativas oficiais de provimento habitacional para a população de menor renda pode-se dividir em três fases: a primeira com a intervenção 
estatal através dos IAPsiii e da Fundação Casa Popular (FCP), criada em 1946, a segunda em 1964 caracterizada pela implantação do Banco Nacional de Habitação (BNH), e a terceira representada pelo período pós-BNH, extinto em 1986 (SANVITTO, 2010, p.5).

A partir de 1986 as atribuições relativas às questões da moradia de interesse social são transferidas para a Caixa Econômica Federal. E com a criação do Ministério das Cidades, em 2003, que instituiu em 2009 o Programa Minha Casa, Minha Vidaiv.

Buscando adequar às necessidades de moradia à população de baixa renda, em 2017 foi criado o PMCMV - Habitação Urbana, com quatro faixas de renda, sendo o Faixa 1v, o objeto deste estudo (CAIXA, 2017).

Com sua base econômica marcada, historicamente, pelas atividades mineradoras e sendo destaque nacional na produção deste minério, a região do sul catarinense, cresceu sem preocupação com a infraestrutura urbana futura. Assim, a atividade mineradora foi quem definiu o espaço urbano, modificando o ambiente comprometendo a paisagem natural, inclusive os recursos hídricos (PAGANI, 2013, p.5).

Os primeiros registros que se tem de vilas de operários na região sul de Santa Catarina são as construídas, alugadas e financiadas pelas empresas de extração do carvão aos seus empregados. Sendo que as primeiras habitações eram pequenos casebres em madeira, sem banheiro vinculado à residência, e localizavam-se próximos às minas formando as primeiras vilas operárias mineiras. E estas vilas que foram construídas pelas empresas mineradoras, tinham o intuito de continuar o controle disciplinar dentro do ambiente de trabalho e também no cotidiano dos trabalhadores nos horários fora do expediente, inclusive em sua moradia.

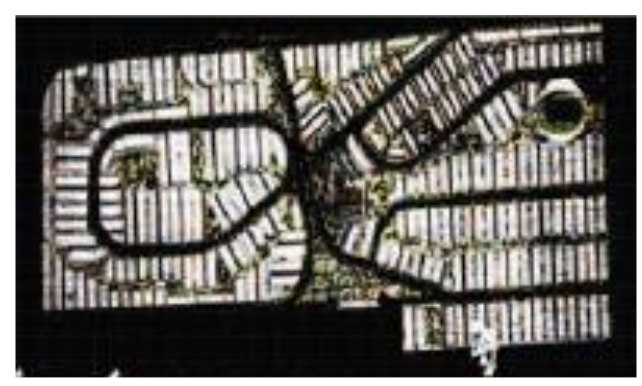

Figura 1 - Desenho artístico original do Loteamento Cidade dos Mineiros, Criciúma/SC, ano 1957 -

Fonte: COLOSSI (2005)

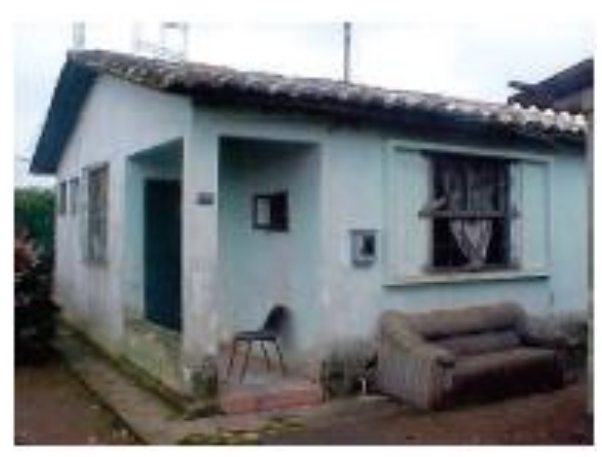

Figura 2 - Vista de casa sem alterações (atual Bairro Cidade Mineira Velha) Fonte: COLOSSI (2005) 
Fazem parte deste momento de criação das vilas operárias o Loteamento Cidade dos Mineiros, de 1957, com uma implantação formando um desenho racionalista (Figura 1), segundo Colossi (2005, p.51), constituída por 1.775 unidades habitacionais em alvenaria convencional (Figura 2) com 60,06 $\mathrm{m}^{2} \mathrm{de}$ área total.

A partir da década de 1940, e com o estímulo oficial do Governo Vargas, as atividades mineradoras da Carbonífera Próspera, induzem a expansão de outras vilas operárias (Figura 3), cujas habitações possuíam uma tipologia de pequenas dimensões erguidas em madeira com cobertura em telhas cerâmicas, segundo Vieira (2001, p.62) (Figura 4).

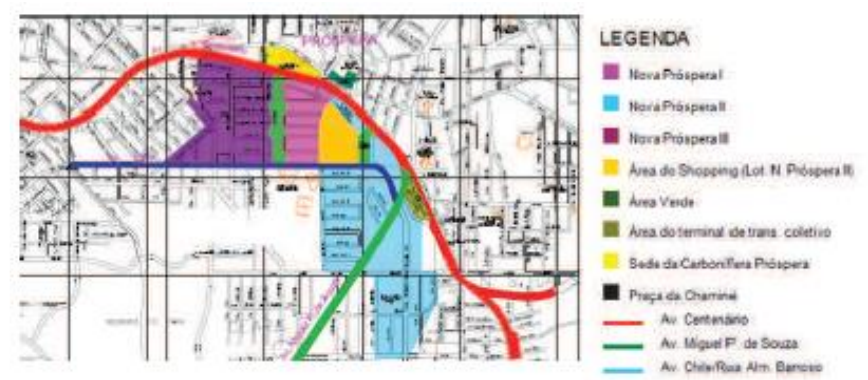

Figura 3 - Mapa com a ocupação do Loteamento Nova Próspera I, Il e III Fonte: VIEIRA (2001)

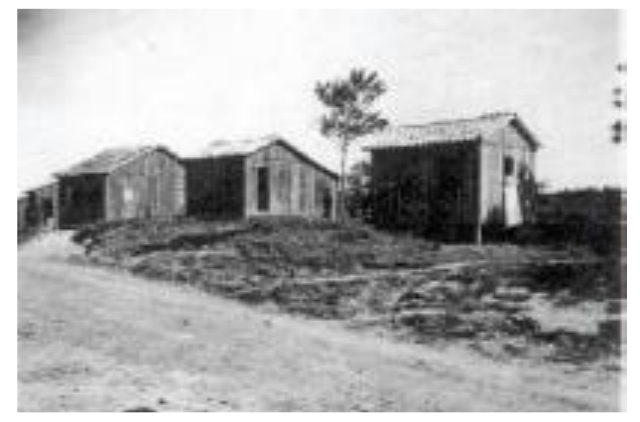

Figura 4 - Tipologia habitacional da primeira Vila Operária, Bairro Próspera, década de 1940 -

Fonte: VIEIRA (2001)

Pagani (2013, p.8) informa que a última ocupação territorial ocorrida destinada a garantir habitação aos mineiros deu-se junto à Mina Quatro, cujo loteamento, de concepção modernista, recebeu o mesmo nome, e o projeto previa a execução de 647 lotes populares. Com desenho concebido pelos arquitetos Carlos Weidman Filho, Décio Gomes Góes e Maria Inês Bay Frydberg, finalizado em 1980 (Figura 5).

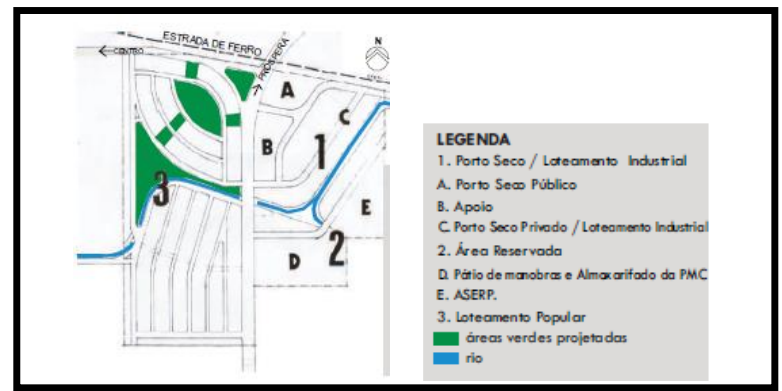

Figura 5 - Mapa do projeto Mina 4 Fonte: VIEIRA (2001) 
Criciúma e região só vão ver alguma movimentação mais efetiva, novamente, relacionadas à retomada da construção de habitações de interesse social a partir de 2003, com o PMCMV (Figura 6).

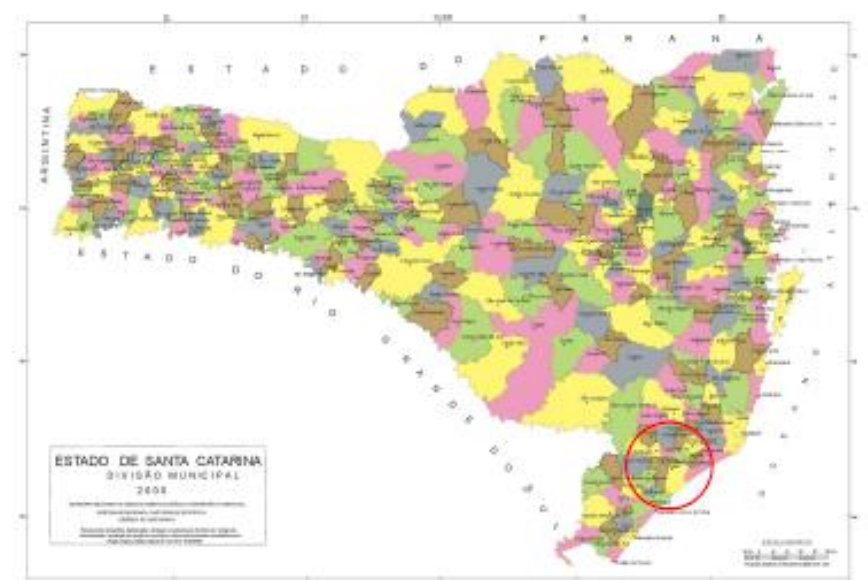

Figura 6 - Mapa do Estado de Santa Catarina - Divisão Municipal, com destaque para a região onde estão localizados os empreendimentos do Minha Casa, Minha Vida, analisados -

Fonte: Mapa da Secretaria de Estado do Desenvolvimento, Econômico e Integração do Mercosul (2000) modificado pela autora. Disponível em <http://www.sul-sc.com.br/afolha/cidades/image/mapasc.htm>. Acesso em: 14 maio 2017

\section{AS HABITAÇÕES DE INTERESSE SOCIAL - OBJETOS DESTE ESTUDO}

Para constituir a amostra deste estudo buscou-se quatro empreendimentos localizados na área de abrangência, e em empreendimentos que apresentassem similaridade nos métodos construtivos, padrões e acabamentos.

Importante saber que, segundo a CAIXA/MCidades (2017), a área útil da UH padrão para casas do PMCMV deverá ter $32 \mathrm{~m}^{2}$, e é composta por 02 (dois) dormitórios, banheiro, estar, jantar, cozinha e área de serviço.

\subsection{Empreendimento A}

Localizado no município de Içara, este condomínio agrega em sua área 212 unidades habitacionais isoladas, em uma implantação linear formada por quatro fileiras de casas (Figura 7).

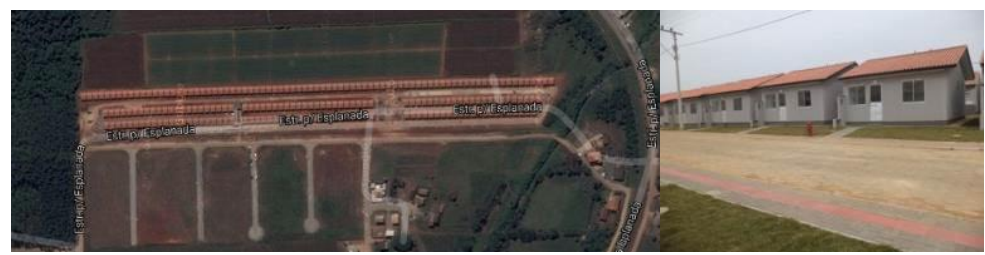

Figura 7 - Vista área do Empreendimento A e fachada da UH Padrão Fonte: Google Earth, modificado pela autora. Acesso em: 14 jun. 2016

\subsection{Empreendimento B}

Localizado também em Içara, este condomínio apresenta implantação linear composta por duas fileiras de habitações, totalizando 100 unidades habitacionais de casas geminadas (Figura 8). 


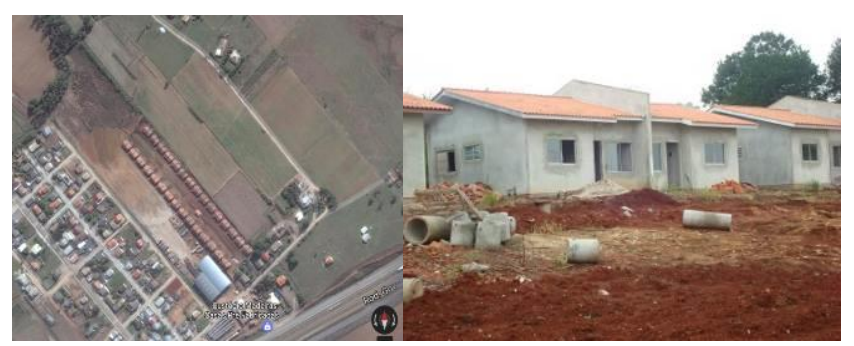

Figura 8 - Vista área do Empreendimento B e fachada da UH Padrão -

Fonte: Google Earth, modificado pela autora. Acesso em: 14 jun. 2016

\subsection{Empreendimento $\mathrm{C}$}

Localizado em Balneário Rincão, este empreendimento, composto por 100 unidades habitacionais, é formado por módulos de quatro unidades geminadas. Tem sua implantação em formato de dois retângulos concêntricos (Figura 9).

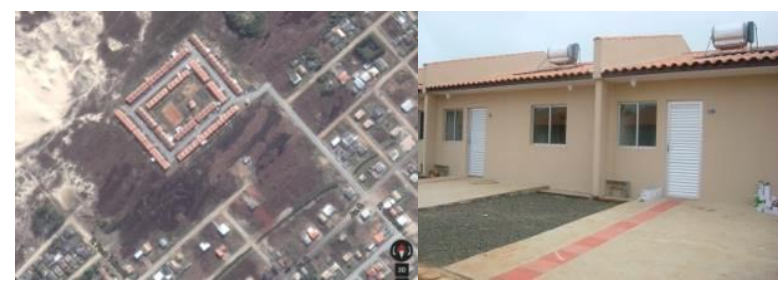

Figura 9 - Vista área do Empreendimento C e fachada da UH Padrão -

Fonte: Google Earth, modificado pela autora. Acesso em: 14 jun. 2016

\subsection{Empreendimento D}

Localizado no município de Forquilhinha, é composto por 144 unidades habitacionais, formado por conjuntos de duas casas geminadas (Figura 10).

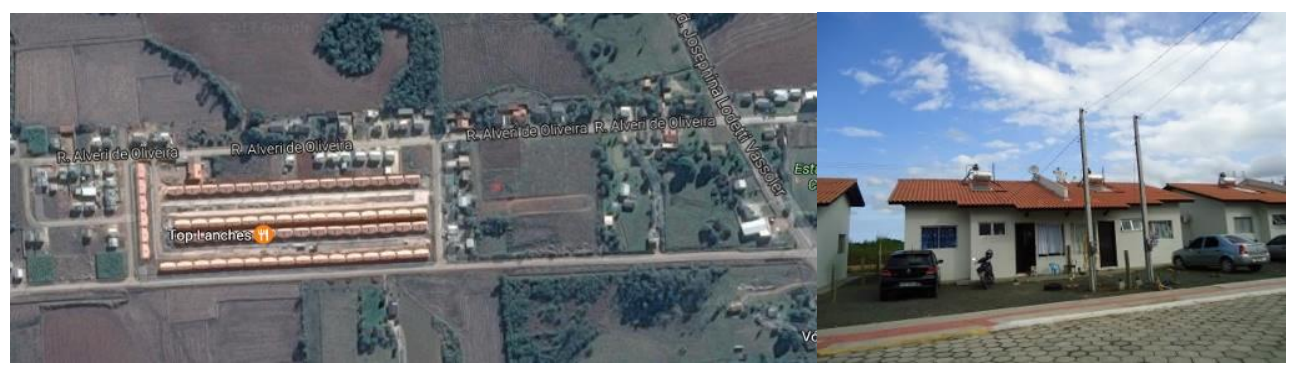

Figura 10 - Vista área do Empreendimento D e fachada da UH Padrão Fonte: Google Earth, modificado pela autora. Acesso em: 14 jun. 2016

\section{MÉTODO}

A análise acerca do funcionamento das UH de interesse social se baseou em pesquisas de cunho qualitativo e quantitativo, distribuídas por bibliografia diversa.

\subsection{Geometria}

Com o foco nas UH cabe entender a conceituação de Clark e Pause (1996, p.6) que diz que "a geometria é uma ideia geratriz da arquitetura que 
engloba os princípios da geometria do plano e do volume para delimitar a forma construída".

Segundo Martins (1999, p.31)

a solução geométrica obtida pelo arranjo físico representa por outro lado um dos fatores delimitantes do custo da edificação, uma vez que a formação de um determinado ambiente e da própria habitação é processada a partir do enclausuramento da área por meio das paredes, as quais formam figuras geométricas com diferentes relações perímetro/área.

O domínio das possibilidades de combinações da geometria, enquanto forma geratriz da arquitetura, esta relacionado com as dimensões e as quantidades; e como objeto da análise centra-se nos conceitos de tamanho, situação, forma e proporção.

Para a análise geométrica dos espaços outros autores propõem diferentes índices do relacionamento da área pelo perímetro de uma figura fechada, como informa Martins (1999, p.32) para quem a relação das formas propostas, tanto por Horton (1932) quanto por Haggett (1965), podem ser, ambas, traduzidas em uma mesma equação.

Relação de forma em Horton (1932) e Hagett (1965):

Onde, $A$ = Área da figura;

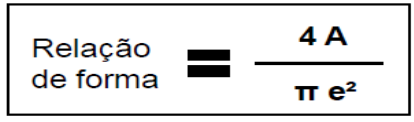

$\Pi(\mathrm{Pi})=$ Constante matemática;

e = Diâmetro ou eixo menor da figura.

\subsection{Forma}

A forma de uma edificação é a parte mais aparente e que the dá os limites exteriores do corpo.

De acordo com a forma adotada têm-se um melhor aproveitamento do espaço das UH, caracterizada pelas dimensões destes espaços.

Quanto mais regular for a forma melhor vai ser o desempenho do ambiente, como observado pelas fórmulas matemáticas propostas por March (1970) quanto à performance do projeto e por Mascaró (1985) quanto ao índice de compacidade.

Performance do projeto, por March (1970):

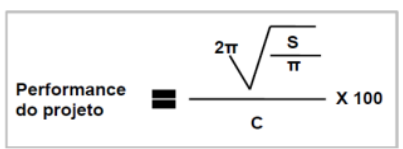

Onde, $S$ = Área total do pavimento;

$\Pi(\mathrm{Pi})=$ Constante matemática;

$C=$ Perímetro total do pavimento.

Índice de compacidade, por Mascaró (1985): 


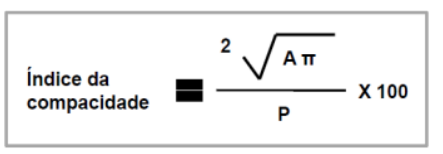

Onde, $\mathrm{A}=$ Área da figura;

$\Pi(\mathrm{Pi})=$ Constante matemática;

$\mathrm{P}=$ Perímetro da figura.

O resultado para o índice de compacidade corresponde à raiz quadrada da área da figura (A) multiplicada por $\Pi(\mathrm{Pi})$, dividido pelo perímetro da figura $(\mathrm{P})$, multiplicado por 100 (cem).

Em relação à performance de projeto, quanto maior o valor encontrado, considera-se o projeto com a melhor performance.

\subsection{Funcionalidade}

Segundo Merleau-Ponty (1971 apud Rifrano (2006, p.58) "o corpo é o ponto de ancoragem que permite o estabelecimento do nível espacial, e consequentemente, a orientação dos eventos". E continua:

O corpo humano é o que estabelece as conexões entre as coisas, arranjando-as significativamente para os seus propósitos e com suas ações.

Afirma ainda que "o espaço arquitetônico é, pois, o palco do espetáculo do cotidiano" (MERLEAU-PONTY, 1971 apud RIFRANO, 2006, p.58). Não sendo diferente nos espaços da UH de interesse social.

Desta forma, as conexões estabelecidas pelo corpo humano com os espaçosuso através das circulações referendam os conceitos de Clark e Pause aplicados neste estudo.

Clark e Pause $(1996$, p.5) relacionam a circulação - componente estático - e o uso do espaço ou espaço-uso - componente dinâmico - como os componentes mais relevantes dos edifícios. Enquanto que o uso do espaço é o foco primeiro da tomada de decisão na arquitetura e faz referência à função, a circulação é o meio pelo qual se associam as diversas áreas em um projeto de uma edificação.

Ainda, segundo Clark e Pause (1996, p.5) a circulação pode estar definida em um espaço destinado exclusivamente ao movimento relacionando a circulação - componente estático -, ou incluída dentro do uso do espaço componente dinâmico.

Os modelos gerados têm a possibilidade de sugerir organizações centralizadas, lineares ou agrupadas. Sendo que a relação entre a circulação e os espaços-uso pode indicar condições de privacidade e de conexão.

Para Martins (1999, p.30) "[...] as paredes assumem o principal fator definidor da funcionalidade arquitetônica dos ambientes", derivada da relação perímetro/área.

\section{APLICAÇÃO DO MÉTODO E AVALIAÇÃO DA PESQUISA}

Os parâmetros analisados têm seus resultados apresentados em uma planilha comparativa (Tabela 02) onde estão postados os dados encontrados com a aplicação dos itens de análise quanto à geometria, à forma e à 
funcionalidade, e na qual as características sejam elencadas como quantitativas - geometria e forma - e como qualitativa - funcionalidade.

\subsection{Geometria}

A concepção de um espaço, como foi visto, deve considerar o uso de formas geométricas regulares buscando uma melhor composição final, já que as formas curvas, como círculos e as formas irregulares, como trapézios, por exemplo, dificultam a organização dos espaços.

Para chegar aos resultados apresentados, foi utilizada a fórmula de Horton e Hagett (Relação da forma).

Neste caso, o menor valor obtido revela que a forma escolhida para configurar o espaço está próxima do ideal.

- UH Padrão do Empreendimento $A=1,566$

- UH Padrão do Empreendimento $B=1,376$

- UH Padrão do Empreendimento $C=1,566$

- UH Padrão do Empreendimento $D=1,128$

\subsection{Forma}

Considerando, segundo Martins (1999), que quanto mais regular a forma melhor o desempenho do ambiente, e aplicando as fórmulas para determinar a performance do projeto por March e a do índice de compacidade definida por Mascaró.

\subsubsection{Performance de projeto}

Através da análise da performance do projeto determinada por March (Martins, 1999, p.32), que está relacionada à área total do pavimento (S) e ao perímetro total do pavimento (C), é possível obter o valor de desempenho de cada uma das UH. E quanto mais alto for o valor resultante, melhor é o desempenho de um projeto.

- UH Padrão do Empreendimento $A=13,062$

- UH Padrão do Empreendimento $B=12,207$

- UH Padrão do Empreendimento $C=13,062$

- UH Padrão do Empreendimento $D=12,322$

\subsection{2 Índice de compacidade}

Como visto anteriormente, Mascaró (2004, p. 38), através de sua fórmula que define o índice de compacidade, e que se baseia em uma relação da área (A) sobre o perímetro (P), informa que quanto mais próximo de 100, melhor o desempenho do ambiente analisado. Entretanto, sabe-se que, como demonstrado na Tabela 1, a aplicação das fórmulas do círculo, do quadrado e do retângulo nos conduzem a resultados máximos de $50 \%$ (cinquenta por cento).

- UH Padrão do Empreendimento $A=\mathbf{4 4 , 0 7 8}$

- UH Padrão do Empreendimento $B=43,321$

- UH Padrão do Empreendimento $C=44,078$ 
- UH Padrão do Empreendimento $D=42,952$

\subsubsection{Funcionalidade}

Considerando que a circulação e o uso do espaço são os componentes dos ambientes das edificações, é importante relacioná-los entre si, para que seja possível apontar os componentes estáticos e os componentes dinâmicos, através dos parâmetros definidos por Clark e Pause (1996).

Ao analisar o uso dos espaços das UH dos empreendimentos estudados podese observar que alguns possuem os espaços de uso mais concentrados e outros mais dispersos, ou uns mais organizados e outros nem tanto.

Para que se possa diferenciar os elementos estáticos (circulação) dos elementos dinâmicos (uso do espaço), optou-se por utilizar uma linha tracejada indicando o melhor percurso para o usuário alcançar todos os ambientes, ou todos os espaços-uso, com menor desperdício de tempo e de deslocamento (Figura 11).

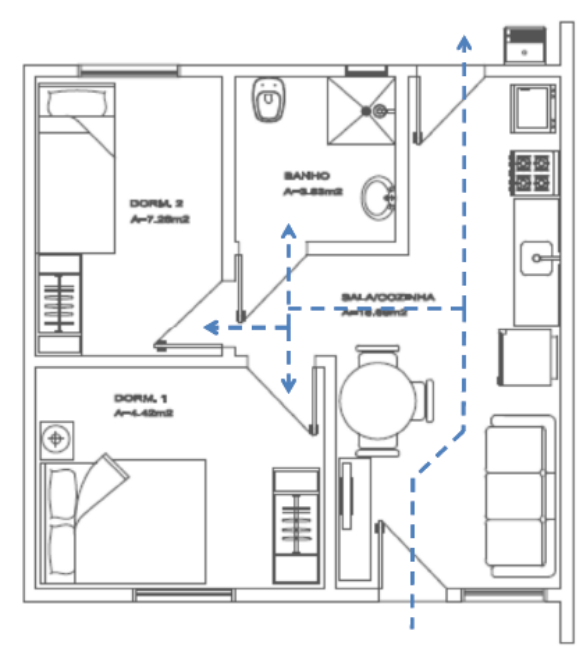

Empreendimento A

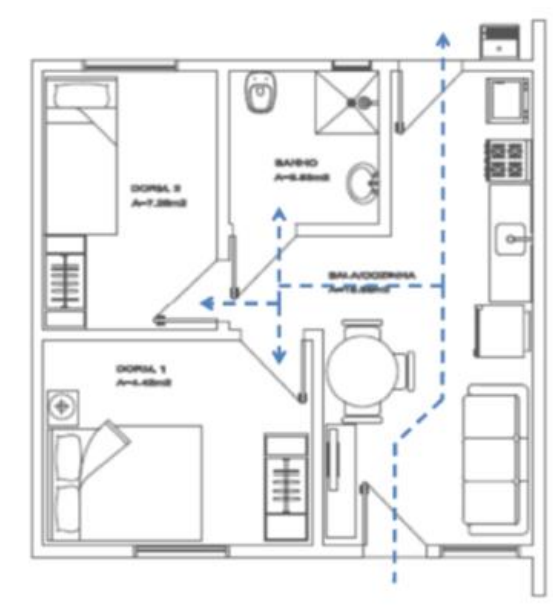

Empreendimento C

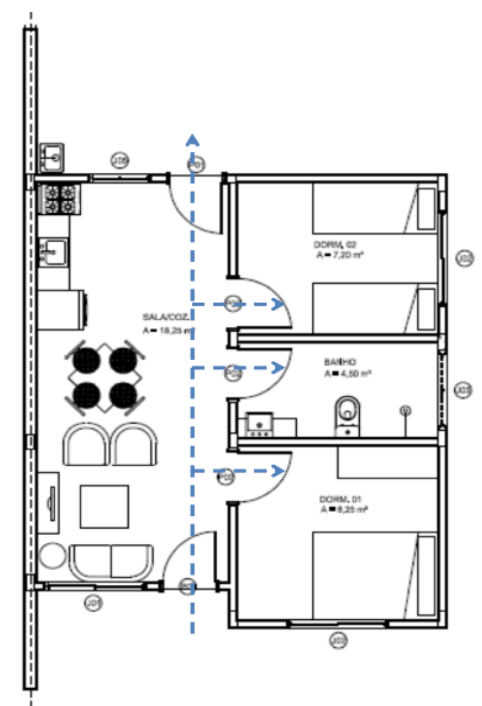

Empreendimento B

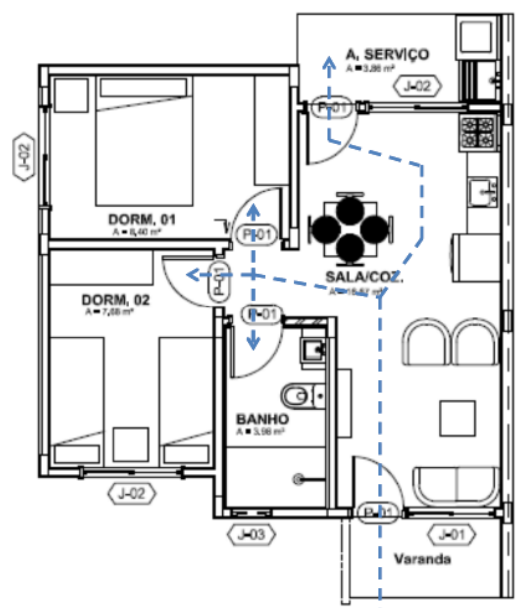

Empreendimento D

Figura 11 - Plantas humanizadas com identificação dos componentes estáticos e dinâmicos das UH - 
Tabela 1 - Quadro comparativo avaliativo

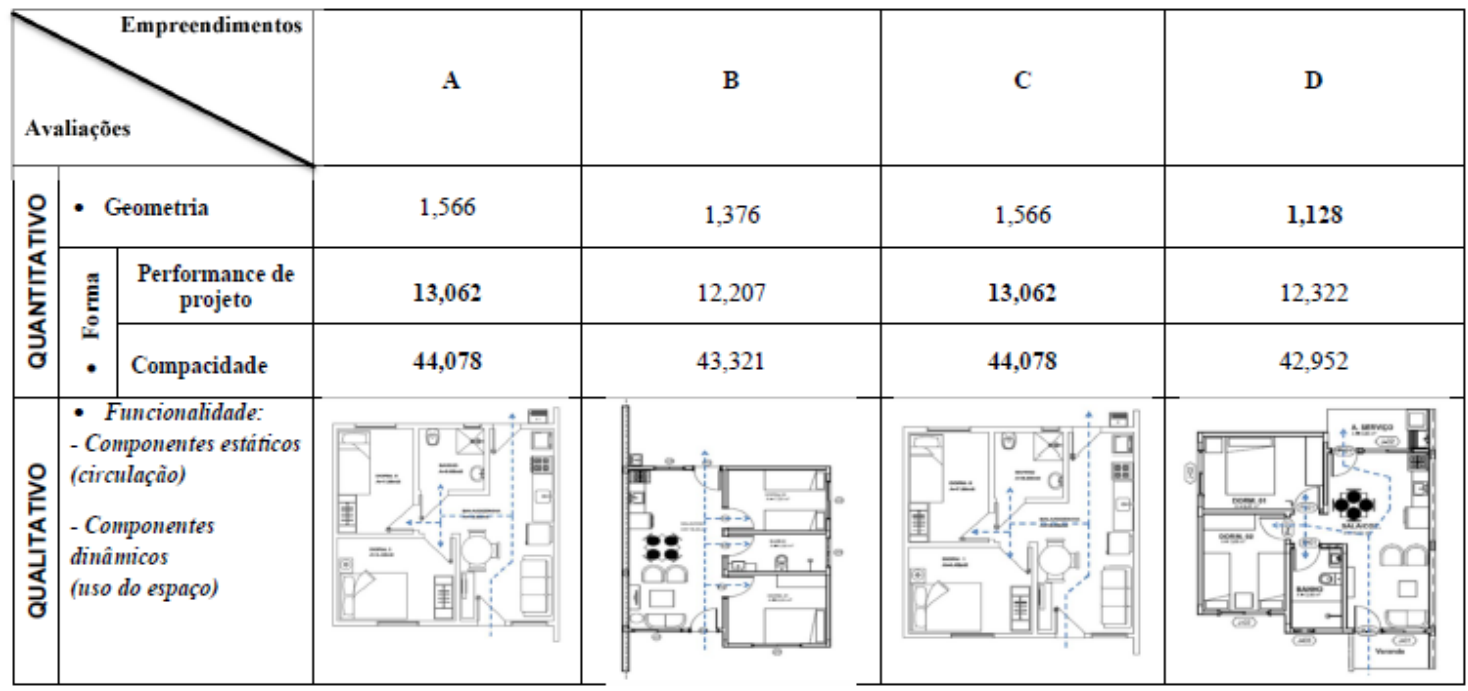

Fonte: Elaborado pela autora (2017)

Nos casos estudados, as plantas analisadas possuem uma configuração geométrica retangular, muito similares entre si.

Para constituir o corpo deste estudo buscou-se quatro empreendimentos na mesma área de abrangência e que apresentassem similaridade nos métodos construtivos, padrões e acabamentos, sendo O "Empreendimento A" e o "Empreendimento B" ambos localizados em Içara/SC, O "Empreendimento C" localizado em Balneário Rincão/SC, e o "Empreendimento D" localizado em Forquilhinha/SC.

A planta com melhor arranjo geométrico é a do empreendimento $D$, que apesar de sua composição geométrica irregular, consegue se apropriar de um desenho menos ortodoxo para obter um melhor índice.

Formalmente o contorno regular das UH é o fator que facilitará a organização dos ambientes. E assim, através da geometria regular, obtêm-se a forma que proporciona um melhor desempenho das UH, compostas pela alta performance de projeto e por um índice de compacidade alto. Nestes aspectos os empreendimentos que obtiveram os melhores índices foram os $A e$ C, com a mesma configuração projetual.

A planta mais funcional através da combinação dos componentes estáticos e dinâmicos é a do empreendimento $B$, com a distribuição dos ambientes de maneira menos fragmentada, possibilitando melhor movimentação do usuário pelo ambiente, sem barreiras.

\section{CONCLUSÕES}

A metodologia adotada permitiu determinar a qualidade dos dados analisados, a partir dos parâmetros definidos e apontar as composições mais favoráveis para um melhor rendimento dos espaços construídos das habitações de interesse social.

Observa-se que há um padrão muito similar na composição dos espaços, e que os parâmetros avaliativos, como a forma, a geometria e a funcionalidade, 
é que podem determinar uma melhor configuração e a melhor habitabilidade.

Um fator importante a ser ressaltado é o da geometria e a relação da forma, que preconiza que quanto mais compacto o ambiente, melhor será o desempenho da forma.

Esse fator, por sua vez, acaba agindo sobre a forma - performance e compacidade de projeto - dos empreendimentos, que se refletem nas UH.

Sendo assim, para que se possa resolver as questões relativas à qualidade das UH padrão das habitações de interesse social, faz-se necessário alguns ajustes nas plantas, no que tange a dimensões e, consequentemente, disposição dos ambientes.

\section{REFERÊNCIAS}

ASSOCIAÇÃO BRASILEIRA DE NORMAS TÉCNICAS. NBR 6023: informação e documentação: referências: elaboração. Rio de Janeiro: 2002.

BONDUKI, N. Origens da habitação social no Brasil: arquitetura moderna, lei do inquilinato e difusão da casa própria. 4. ed São Paulo: Estação Liberdade, 2004. 342 p.

BRASIL. Constituição (1988). Capítulo II, Dos Direitos Sociais; art. 6 , com redação alterada pela Emenda Constitucional $n^{\circ}$ 64, de 4 de fevereiro de 2010. Disponível em: <http://www.planalto.gov.br/

ccivil_03/constituicao/constituicao.html>. Acesso em: 27 nov. 2015.

Estatuto da Cidade. Lei $\mathrm{n}^{\circ} \mathbf{1 0 . 2 5 7}$, de 10 de julho de 2001. Disponível em: <http://www.planalto.gov.br/ccivil_03/leis/leis_2001//10257.html>. Acesso em: 27 nov. 2015.

CAIXA ECONÔMICA FEDERAL. Demanda habitacional no Brasil. Brasília: CAIXA, 2017. $173 \mathrm{p}$.

CLARK, R. H.; PAUSE, M. Arquitectura: temas de composición. 3. ed. México: Gustavo Gili, 1997. 274 p.

CHING, F. D. K. Trad. Julio Fischer. Dicionário visual de arquitetura. 1. ed., 2. tir. São Paulo: Martins Fontes, 1999. 319 p.

COLOSSI, G. E. O processo de apropriação do espaço urbano em loteamentos populares: um estudo de caso no loteamento Cidade dos Mineiros -

Criciúma/SC, 2005. 250 p. Dissertação (Mestrado) - Universidade do Extremo Sul Catarinense, Programa de Pós-Graduação em Ciências Ambientais, 2005.

Disponível em: <http://www.bib.unesc.net>. Acesso em: 17 fev. 2013.

FUNDAÇÃO JOÃO PINHEIRO. GOVERNO DE MINAS GERAIS. Déficit habitacional de Santa Catarina: 2013-2014. Disponível em:

<http://www.fjp.mg.gov.br/index.php/docman/cei/informativos-ceieventuais/634-deficit-habitacional-06-09-2016/file>. Acesso em: 02 mai. 2017.

MARTINS, D. N. Metodologia para determinar e avaliar a qualidade e o custo da solução geométrica do projeto arquitetônico de apartamentos. 1999. 197 f. Tese (Doutorado) - Departamento de Engenharia de Produção, Universidade Federal de Santa Catarina, Florianópolis, 1999. 
MASCARÓ, J. L. O custo das decisões arquitetônicas. 4. ed. Porto Alegre: Masquatro, 2006. 192 p.

MOTTA, L. D. A questão da habitação no Brasil: políticas públicas, conflitos urbanos e o direito à cidade. Disponível em:

<http://conflitosambientaismg.lcc.ufmg.br/wp-content/uploads/2014/04/TAMC -MOTTA_Luana_-_A_questao_da_habitacao_no_Brasil.pdf>. Acesso em: 14 maio 2017.

PAGANI, H. B. Habitação de interesse social em Criciúma. 2013. 59 f. Trabalho de Conclusão de Curso (Graduação) - Curso de Curso de Arquitetura e Urbanismo, Universidade do Extremo Sul de Santa Catarina, Criciúma, 2013.

RIFRANO, L. Avaliação de projetos habitacionais: determinando a funcionalidade da moradia social. 1. ed. São Paulo: Ensino Profissional, 2006. $161 \mathrm{p}$.

SANVITTO, M. L. A. Habitação coletiva econômica na arquitetura moderna brasileira entre 1964 e 1986. 548 p. Tese (Doutoramento em Arquitetura). Universidade Federal do Rio Grande do SUl, PROPAR, Porto Alegre, 2010.

VIEIRA, J. L. Os projetos Nova Próspera e Mina-4 na configuração espacial da Grande Próspera em Criciúma. 2001. 236 p. Dissertação (Mestrado) Universidade Federal de Santa Catarina, Centro de Filosofia e Ciências Humanas, Departamento de Geociências. Disponível em: <http://www.brasil.gov.br/noticias/arquivos/2010/01/21/cadunico>. Acesso em: 15 nov. 2016.

\footnotetext{
' Dados disponibilizados à Hélen Bernardo Pagani por Ana Maria Ramos Meller - então representante da Gerência de Habitação da Secretaria Municipal do Sistema Social de Criciúma. Dados coletados em 22.02.2013.

ii Déficit baseado no Cadastro Único do Governo Federal para Programas Sociais (CadÚnico).

iii IAP - Instituto de Aposentadorias e Pensões.

iv Programas federais para a política habitacional, criados em 2003, como o PACiv e o PMCMViv, criados para dar condições de acesso à moradia aos cidadãos, aliada à atuação do Estado, através do fornecimento de subsídios, para que as famílias de menor poder aquisitivo tenham acesso à casa própria.

$\checkmark$ Faixa 1 - Famílias com renda mensal até $R \$ 1.800,00$ (Hum mil e oitocentos Reais).
} 